\title{
Um estudo bibliográfico sobre o enfoque da família nas políticas públicas de atenção a criança e adolescentes
}

\author{
A bibliographic study on the family focus in public policies attention of the children and \\ adolescent
}

\author{
Grazieli Rosa Tenório* \\ Débora Braga Zagabria**
}

\begin{abstract}
Resumo:
No Brasil, a elaboração de políticas públicas para a infância e a adolescência vem sofrendo transformações, sobretudo a partir da década de 1990. O reconhecimento da centralidade da família nas políticas e programas sociais tornou-se praticamente consensual e tem gerado debate em âmbito nacional e internacional. Com essa referência, apresentamos os resultados de uma pesquisa bibliográfica que se propôs analisar, na produção bibliográfica brasileira, em periódicos de psicologia indexados na base de dados da Scielo, como as famílias têm sido tratadas na elaboração e implementação das políticas públicas de proteção à criança e ao adolescente, no período de 1990 a julho de 2010. A pesquisa foi realizada a partir das palavras-chaves "família", "crianças e adolescentes" e "políticas públicas". Identificamos e localizamos vinte e nove artigos em seis revistas distintas, dos quais foram selecionados doze, sendo que os conteúdos temáticos encontrados nos trabalhos foram categorizados em cinco núcleos. Embora a maioria dos autores pesquisados reconheça a importância da família como primeiro grupo de socialização, independentemente de suas configurações, os resultados confirmam a fragilidade das políticas públicas e programas sociais no Brasil com centralidade na família para a proteção e atendimento da criança e do adolescente.
\end{abstract}

Palavras-chave: Família. Políticas públicas. Crianças e adolescentes.

\begin{abstract}
:
Public politics for children and adolescents in Brazil are suffering transformations, especially from the $90 \mathrm{~s}$ on. The recognition in the centrality of the family in the politics and social programs became practically consensual and it has been generating discussions in national and international extent. With that reference, we developed and present here the results of a bibliographical research that intended to analyze, through the Brazilian bibliographical production, in psychology newspapers indexed in the Scielo data base, how the families have been approached in the elaboration and
\end{abstract}

\footnotetext{
* Psicóloga, Especialista em Saúde Mental e em Gestão de Políticas Públicas para a Infância e Juventude. Psicóloga no Centro de Atenção Psicossocial Infantojuvenil (CAPSi) em Maringá-PR. grazieli.rosa@gmail.com

** Assistente Social, Doutora em Serviço Social pela Pontifícia Universidade Católica de São Paulo. Professora adjunta do departamento de Serviço social da Universidade Estadual de Londrina. debbz@sercomtel.com.br
} 
implementation of the public politics of protection to children and adolescents, from 1990 to July 2010. The research was accomplished searching from the key words "family", "children and adolescents" and "public politics". We identified and located twenty-nine articles in six different journals, twelve of them were selected after text reading. The thematic contents, found in the papers were classified according to five nuclei. Although most of the researched authors recognize the importance of the family as first socialization group, independently of their configurations, the results confirm the fragility of the public politics and social programs in Brazil with centrality in the family for the protection and assistance to children and adolescents.

Keywords: Family. Public politics. Children and adolescents.

\section{Introdução}

A elaboração das políticas públicas para a infância e a adolescência no Brasil vem sofrendo transformações ao longo das últimas décadas. Faz parte deste mesmo processo o lugar destinado às famílias na implementação de tais políticas. Nesse contexto, torna-se fundamental compreendermos tanto as políticas sociais para a infância e a adolescência como a própria instituição familiar como parte integrante dessas determinações sócio-históricas. Pretendemos, então, compreender como a família tem sido tratada pelas políticas públicas voltadas para o atendimento da criança e do adolescente no Brasil, com o intuito de identificarmos se ela tem sido considerada como sujeito ou simplesmente depositária dessas.

Primeiramente, convém destacar que o conceito de família

[...] é polissêmico, com vários sentidos e significados. No sentido mais restrito, ele se refere ao núcleo familiar básico. No sentido mais amplo, ao grupo de indivíduos vinculados entre si por laços consanguíneos, consensuais ou jurídicos, que constituem complexas redes de parentesco atualizadas de forma episódica por meio de intercâmbios, cooperação, solidariedade, com limites que variam de cultura, de uma região e classe social a outra (TURIÁN apud CARVALHO; ALMEIDA, 2003, p. 111).

A família pode ser pensada sob diferentes aspectos:

[...] como unidade doméstica, assegurando condições materiais necessárias à sobrevivência, como instituição, referencial e local de segurança; como um conjunto de laços de parentesco; como um grupo de afinidade, com variados 
graus de convivência e proximidade e de tantas outras formas. Existe uma multiplicidade de formas e sentidos da palavra família, construída com a contribuição das várias ciências sociais e podendo ser pensada sob os mais variados enfoques por meio de diferentes referenciais acadêmicos. (VILHENA apud OLIVEIRA, 2009, p. 113).

De acordo com Carvalho e Almeida (2003), o arquétipo de família conjugal, tradicional nas sociedades contemporâneas, é constituído pelo casal e por seus filhos não emancipados, residentes em um mesmo domicílio. Entretanto, as crescentes transformações desse modelo e o surgimento de uma realidade muito mais plural revelam uma proporção crescente de famílias que não se enquadram mais nesse padrão.

Os autores acrescentam que a diversidade de tipos ou modelos nas estruturas familiares não é, de maneira alguma, um processo novo e que a idealização da família nuclear mostra-se como uma invenção moderna, tendo atingido seu auge na década de 1950, sustentada pela difusão da cultura em massa no período que se seguiu à Segunda Guerra Mundial (CARVALHO; ALMEIDA, 2003).

O avanço da urbanização, da industrialização e da modernização das sociedades provocou transformações inclusive nos grupos familiares. Houve, por exemplo, um aumento da presença feminina no mercado de trabalho, a divulgação e utilização de práticas anticoncepcionais, bem como a fragilização dos laços matrimoniais, com o aumento dos divórcios e de novos acordos sexuais.

Ao primeiro olhar, tem-se a impressão de que as famílias encontram-se "desestruturadas" ameaçadas ou a caminho da extinção, porém uma leitura mais cuidadosa revela sua enorme plasticidade e capacidade para a mudança e para a adaptação diante das transformações econômicas, sociais e culturais mais amplas. Além disso, persiste sua relevância enquanto espaço de sociabilidade e socialização primárias, de solidariedade e de proteção social.

Segundo Mioto (1997), não podemos mais falar em família, mas, sim, em famílias, uma vez que o uso da palavra no plural procura abarcar a diversidade de arranjos familiares existente na sociedade. Acrescenta-se que a tarefa primordial das famílias refere-se ao cuidado e à proteção de seus membros, constituindo-se em um lugar privilegiado de preservação da 
vida. São os afetos que impulsionam as relações familiares, sejam eles de amor, ódio, inveja, gratidão ou qualquer outro, e é nesse espaço que a criança aprende a reconhecer-se como única, formando sua identidade, e também como pertencente a um grupo. Tais aspectos são fundamentais para o processo de humanização e indispensáveis à inserção de cada indivíduo no mundo social mais amplo (MIOTO, 1997).

Assim identificamos que, embora haja questionamentos acerca da centralidade e do futuro das famílias na sociedade contemporânea, suas funções sociais e responsabilidades continuam tendo relevância e sendo ainda muito pertinentes (CARVALHO; ALMEIDA, 2003).

Além de Carvalho e Almeida (2003), Petrini (2003), Kaloustian e Ferrari (1994), Serapioni (2005) e Mioto (1997) também defendem o papel da família enquanto primeiro grupo de socialização, recomendando que a reforma das políticas e dos programas sociais governamentais brasileiros tenham a família como eixo prioritário de suas ações.

Serapioni (2005) afirma que, a partir da década de 1990, o debate, em âmbito nacional e internacional, tem se voltado para a mudança na relação entre a família e as políticas sociais. O reconhecimento na centralidade da família tornou-se praticamente consensual, embora as políticas e programas sociais no Brasil sejam, até o presente momento, insuficientes para atender a esta demanda.

Não obstante, tal posicionamento mostra-se relativamente novo quando consideramos o papel ocupado pela família na implementação das políticas públicas ao longo das últimas décadas. Retrospectivas históricas indicam que poucas referências foram feitas à família brasileira das camadas populares ou pobres, e, quando feitas, contribuíam para a construção do paradigma de incompetentes e incapazes de zelar pelo bem-estar de seus filhos (OLIVEIRA, 2009).

Um primeiro período a ser destacado na área de atendimento à infância no Brasil, correspondente ao fim do século XIX e início do século XX, caracterizou-se por medidas higienistas e promoveu o aparecimento da família das camadas populares ou pobres, até então colocada à margem da ordem burguesa. O higienismo foi inserido nas políticas públicas e suas práticas visavam à normatização de valores e comportamentos da infância/família brasileira (OLIVEIRA, 2009; HILLESHEIM; CRUZ, 2008; SILVA JÚNIOR; ANDRADE, 2007). 
A higiene se propôs - e de fato conseguiu - cumprir seu legado: convenceu que, para educar seus filhos, as famílias pobres careciam de recursos não apenas financeiros, mas também morais e intelectuais. Instalado o estigma da incompetência e da falta de conhecimento, a família pobre passou a sofrer forte controle e dominação, sendo, gradativamente, "desautorizada em relação à criação de seus filhos o que de certa forma, contribuiu para denominá-las de 'famílias desestruturadas'”' (OLIVEIRA 2009, p. 115).

As variadas políticas direcionadas à infância, durante a maior parte do século XX, consideravam infância pobre como equivalente à infância perigosa (HILLESHEIM; CRUZ, 2008). Assim, a culpabilização da família e da pobreza abriu espaço para a institucionalização das crianças pobres, e a família, deixada de lado no processo de educação de seus filhos, experimenta a total negação de seu direito de exercer o papel de sujeito na educação dos filhos (SILVA JÚNIOR; ANDRADE, 2007; OLIVEIRA, 2009).

Desde o Pós-Guerra, a família foi "descartada" e considerada substituível por um Estado protetor dos direitos dos cidadãos. Acreditava-se que as políticas públicas seriam capazes de efetivar, por si mesmas, a oferta universal de bens, serviços e proteção.

Não obstante, as expectativas de que o Estado atenderia a todas as demandas de proteção foram derrubadas e ações compartilhadas entre o Estado e a sociedade começaram a ser exigidas. A crise do Estado de Bem-Estar Social contribuiu para a redescoberta da família, das redes primárias e da comunidade como atores fundamentais na efetivação das políticas sociais (SERAPIONI, 2005). Apesar da diversificação nas formas de convivência familiar, a família não perdeu sua importância na sociedade moderna, mas permanece como espaço privilegiado para o exercício inicial da cidadania.

A família, antes descartada, volta, nas últimas décadas, a ser considerada como corresponsável pelo desenvolvimento dos cidadãos (CARVALHO, 2003). Oliveira (2009) aponta que essa mudança coloca a família, gradativamente, na centralidade das políticas públicas, indicando uma superação, paulatina, de práticas discriminatórias e fragmentadas executadas pelo Poder Público no (des)cumprimento de seu papel social.

Somente a partir da década de 1990, denominada a "era da responsabilidade", as políticas públicas direcionaram-se para as crianças na família (CARVALHO, 2003). A 
Constituição Brasileira de 1988 e o Estatuto da Criança e do Adolescente (ECA), de 1990 (BRASIL, 1990), permitiram essa mudança de foco. A família passa a ser considerada como um mecanismo de proteção social, sendo responsabilizada não apenas pela sobrevivência dos indivíduos, mas também pela proteção e socialização de seus componentes (CARVALHO; ALMEIDA, 2003).

De acordo com Carvalho (2003), a família e o Estado passam a ser consideradas instituições fundamentais para o bom funcionamento da sociedade capitalista. À primeira compete oferecer afeto, socialização, apoio mútuo e proteção, e ao Estado oferecer alguns serviços no sistema público que não podem ser adquiridos no mercado de consumo, seja por não estarem disponíveis, seja pelo fato de as famílias não terem condições econômicas para adquiri-los. Essa parceria de corresponsabilidades pode ser claramente observada no artigo 227 da Constituição Federal Brasileira:

É dever da família, da sociedade e do Estado assegurar à criança e ao adolescente, com absoluta prioridade, o direito à vida, à saúde, à alimentação, à educação, ao lazer, à profissionalização, à cultura, à dignidade, ao respeito, à liberdade e à convivência familiar e comunitária, além de colocá-los a salvo de toda forma de negligência, discriminação, exploração, violência, crueldade e opressão (BRASIL, 1988).

Embora a convivência familiar seja um direito fundamental, ela não se dá de maneira homogênea para todos, porque, além de estar profundamente marcada pelas especificidades históricas e culturais, tal vivência está profundamente condicionada pelas diferenças sociais, haja vista que todas as famílias estão inseridas em uma estrutura social (MIOTO, 1997).

O próprio Estatuto da Criança e do Adolescente, ao discutir o direito à convivência familiar e comunitária, no capítulo III, art. 19, determina: "Toda criança ou adolescente tem direito a ser criado e educado no seio de sua família e, excepcionalmente, em família substituta, assegurada a convivência familiar e comunitária" (BRASIL, 1990). Deste modo, pode-se dizer que família e políticas públicas assumem e passam a ter funções correlatas e imprescindíveis ao desenvolvimento e proteção social dos indivíduos. 
Quando consideramos a história das políticas públicas no Brasil, identificamos quão recente é a intenção de promover ações compartilhadas entre o Estado e a família. Podemos, então, indagar se as famílias dispõem de recursos necessários para desempenharem seu papel ou se também precisam ser "cuidadas" e amparadas para "reaprenderem" e/ou "reassumirem" o desempenho de suas funções. De qualquer modo, cabe a questão: quais transformações ainda são necessárias para a real efetivação das ações compartilhadas entre Estado e família no cuidado da criança e do adolescente no Brasil?

De acordo com Gomes e Pereira (2005), a atuação das políticas públicas junto às famílias ainda não se desenvolve com a expressividade necessária. As autoras acrescentam que principalmente a família pobre na falta de políticas públicas fica impedida de atender às necessidades básicas de seus integrantes. Destacam ainda que a família pobre encontra na casa um espaço marcado pela privação, pela instabilidade e pelo esgarçamento dos laços afetivos e de solidariedade. Na casa, quando o espaço de proteção dá lugar ao conflito, fica muito mais difícil superar essa situação, haja vista que, em geral, a família não dispõe de redes de apoio para superar suas dificuldades.

Nas últimas décadas, o Brasil vem impelindo uma imensa desigualdade na distribuição de renda, com elevados níveis de pobreza, fazendo com que parte expressiva de sua população não tenha acesso a condições mínimas de dignidade e cidadania. O país não é pobre, e sim desigual; não existe escassez de recursos, mas uma distribuição desigual deles.

Em termos do produto interno bruto (PIB), o Brasil, a partir do ano de 2009, passa a ocupar o 80 lugar na economia mundial, posição que se consolida e ganha maior visibilidade no ano de 2010. Entre 174 nações, o Brasil é a 8a em produção de riqueza. Por outro lado, se considerarmos o índice de desenvolvimento humano (IDH), no ano 2009 o Brasil classificou-se como a 75a nação nesse aspecto.

De acordo com Bock (1999), temos altos índices de mortalidade infantil e de analfabetismo. A maioria de nossa população se encontra em péssimas condições de vida e não tem acesso aos serviços básicos de saúde e educação. Sem a devida distribuição de renda, nenhum outro problema é resolvido e todas as medidas tornam-se paliativas. 
O modelo econômico no Brasil gera crescente riqueza para poucos e pobreza para muitos. Gomes e Pereira (2005, p 360), referindo-se a esse tipo de modelo econômico, acrescentam que "as desigualdades sociais e de renda se acentuam, afetando as condições de sobrevivência das famílias minando as possibilidades de superação da condição de pobreza, reforçando a dependência dos serviços públicos existentes".

Ainda de acordo com as autoras supracitadas, "a pobreza se evidencia quando parte da população não é capaz de produzir renda suficiente para ter acesso aos recursos básicos que assegurem uma qualidade de vida digna" (GOMES; PEREIRA, 2005, p 360). Entendemos por recursos básicos saúde, água, alimentação, educação, moradia, renda e cidadania. Dessa forma, são considerados pobres aqueles que, temporária ou permanente, não alcançam um mínimo de bens e recursos e estão submetidos a situações de vulnerabilidade e de estresse familiar (MIOTO, 1997; PETRINI, 2003).

São as famílias das camadas populares as que mais sofrem dificuldades, pois não têm garantias, nem mesmo por meio das políticas públicas, acerca das condições mínimas necessárias para o sustento de suas famílias (MIOTO, 1997). A vida familiar, para ser efetiva e eficaz, depende de condições concretas para a sustentação e manutenção de seus vínculos.

Nesse sentido, Gomes e Pereira (2005) apontam que a situação socioeconômica tem sido o fator que mais contribui para as dificuldades vivenciadas pela família, a qual se sente ameaçada e com seus direitos fundamentais violados.

Para Kaloustian e Ferrari (1994, p. 13), "Por detrás da criança excluída da escola, nas favelas, no trabalho precoce urbano e rural e em situação de risco, está a família desassistida ou inatingida pela política oficial". Corroborando tal pensamento, Martins (apud GOMES; PEREIRA 2005) afirma que a criança abandonada é apenas a contrapartida do adulto, da família e da sociedade abandonados.

A questão da família pobre reflete a desigualdade econômica e social no Brasil, pois esse estado de privação de direitos e de esgarçamento dos vínculos familiares atinge a todos os seus membros de forma muito profunda. Diante da ausência de polícias públicas de proteção social para a população carente, é exigido que a família supra essa deficiência sem receber condições para tanto. Ela tem sido reconhecida como uma das alternativas para o 
enfrentamento de determinadas expressões da questão social, o que inclui as questões relacionadas à infância e à adolescência, por exemplo. O Estado diminui suas intervenções na área social e atribui à família uma sobrecarga difícil de ser suportada (GUEIROS, 2002; GOMES; PEREIRA, 2005).

Ao negar direitos básicos que deveriam ser assegurados, o Estado também não propicia condições para uma participação satisfatória da família no desenvolvimento de seus filhos, o que revela a necessidade urgente de políticas públicas com atuação mais expressiva junto às famílias, sobretudo junto àquelas atingidas pela pobreza e pela miséria.

O espaço que a família proporciona para a sobrevivência e proteção integral dos filhos e demais membros não pode ser ocupado pelo Estado. Portanto, as políticas públicas devem estar centradas na família, que precisa ser ajudada e reconhecida como sujeito dessas ações (KALOUSTIAN; FERRARI, 1994).

O Estado deve elaborar políticas públicas de caráter abrangente, que garantam seguridade social e reconheçam a família como sujeito de direitos, capaz de desenvolver as ações propostas. Espera-se, dessa maneira, que a família seja considerada de forma concreta e possua condições de ser autônoma e tenha seus direitos respeitados.

Tais considerações reforçam a urgência de que as políticas públicas sejam mais consistentes e tenham sempre a família como alvo. Para tanto, torna-se imperativa a promoção e o apoio às famílias, principalmente àquelas que se encontram em situação de maior vulnerabilidade. $\mathrm{O}$ seu reconhecimento como agente social ativo e objeto de políticas públicas constitui-se como um fator decisivo na busca dos objetivos prioritários do desenvolvimento humano (MAURÁS; KAYAYAN apud KALOUSTIAN, 1994).

Autores como Maurás e Kayayan (apud KALOUSTIAN,1994), Calderón, Guará, e Carvalho (1994) vêm dedicando-se à discussão deste assunto, alertando sobre a importância da família nas políticas públicas e apontando a necessidade de uma efetiva transformação no aporte das políticas para a criança e o adolescente.

Levando-se em conta as relações entre as políticas sociais e a família, na forma como as políticas sociais estão organizadas, infelizmente a família não está incluída como uma totalidade ou como foco principal de atenção. Entretanto, em vez disso, essas políticas são 
implementadas em função de indivíduos, e a família é sempre vista pelo retrovisor. Pensa-se na criança, no adolescente, no idoso, na pessoa com necessidades especiais, mas não há análise sobre os efeitos das políticas sobre a vida familiar.

Fachinetto (2009) considera o Plano Nacional de Promoção, Proteção e Defesa do Direito de Crianças e Adolescentes à Convivência Familiar e Comunitária (BRASIL, 2006) como o início de uma nova fase da política de atendimento à criança e ao adolescente no Brasil. O Plano valoriza a proposta de superação das ações meramente tutelares para a necessária articulação entre todas as políticas públicas voltadas à garantia da convivência familiar e comunitária enquanto direito das crianças e adolescentes (BRASIL, 2006). Entre as diretrizes do referido plano vale destacar: a centralidade da família nas políticas públicas, a primazia da responsabilidade do Estado no incentivo de políticas que procuram dar apoio à família e o reconhecimento das competências da família para sua organização interna e a superação de suas dificuldades.

Assim, parece-nos importante e justificável realizarmos um estudo bibliográfico com o intuito de compreendermos os espaços destinados - ou não - à família na elaboração/efetivação das políticas públicas de proteção à infância e à adolescência no Brasil, haja vista que se trata de uma área de atuação em constante crescimento e com muitos desafios que ainda precisam ser superados. Além do mais, a sistematização das informações acerca do tema proposto contribuiria tanto para a divulgação de tais elementos e interesses quanto para uma análise do material, que possibilitaria também a detecção não só de possíveis avanços na intersecção Estado e família na implementação das políticas públicas para a infância e a adolescência no Brasil, mas igualmente de lacunas e de questões que necessitariam ser investigadas, permitindo a elaboração de estudos mais aprofundados.

\section{Metodologia}

Estabelecemos como objetivo analisar, na produção bibliográfica e periódicos de psicologia brasileiros indexados na base de dados da Scielo, como as famílias têm sido 
abordadas na elaboração e implementação das políticas públicas de proteção à criança e ao adolescente no período de 1990 a julho de 2010.

O presente estudo apoia-se em pesquisa de natureza qualitativa, por meio da modalidade de pesquisa bibliográfica junto aos periódicos de psicologia indexados nas bases de dados Scielo. A pesquisa foi realizada a partir das palavras-chaves "família", "crianças e adolescentes", "políticas públicas", e os artigos foram selecionados a partir do critério de que as produções escritas brasileiras tenham sido desenvolvidas no período de 1990 a julho de 2010. Identificamos e localizamos vinte e nove artigos relacionados às palavras-chaves supracitadas em seis revistas de psicologia distintas: 1 - Cadernos de Pesquisa; 2 - Estudos de Psicologia - Campinas; 3 - Estudos de Psicologia - Natal; 4 - Psicologia e Sociedade; 5 Psicologia em Estudo e 6 - Psicologia, Reflexão e Crítica. Doze destes artigos foram selecionados após a realização da leitura flutuante dos textos.

A pesquisa bibliográfica concentra-se no levantamento da bibliografia referente ao assunto que se deseja estudar, e, nesse caso em especial, buscamos fundamentos/evidências para apoiar a compreensão do lugar ocupado pelas famílias na elaboração/implementação das políticas públicas de proteção da infância e da adolescência.

Para a organização das informações contidas nas publicações científicas encontradas, foram seguidos os passos preconizados por Minayo (1993): leitura flutuante dos artigos, com o objetivo de estabelecer o primeiro contato com os instrumentos de pesquisa, identificando o objeto, os objetivos do estudo e os seus resultados. Posteriormente, os dados foram registrados sob a forma de fichas de leitura.

Para análise dos dados deste estudo, utilizamos a técnica de Análise de Conteúdo, proposta por Bardin (1979). A Análise de Conteúdo, enquanto técnica de tratamento de dados, tem sido considerada científica e procura a sua lógica na interpretação cifrada de material de caráter qualitativo. Os conteúdos temáticos encontrados nos trabalhos foram categorizados segundo cinco núcleos: A família de todos e de cada um; A família das camadas populares; A criança abandonada como contrapartida da família abandonada; Culpabilização da família; Como a família é referenciada no contexto das políticas públicas para crianças e adolescentes. 


\section{Resultados}

Os resultados da análise dos doze artigos que versam sobre a temática da família nas políticas públicas para a infância e adolescência foram organizados e serão apresentados conforme os núcleos temáticos identificados.

Família de todos e a de cada um

Identificamos que, assim como Carvalho e Almeida (2003), Kaloustian e Ferrari (1994), Serapioni (2005) e Mioto (1997), os autores dos artigos pesquisados também atribuem grande importância ao papel da família no desenvolvimento de cada indivíduo (MACEDO, 1994; AMAZONAS et al., 2003; PRATTA; SANTOS, 2007). Eles defendem a importância da família, pois, além de ser o primeiro grupo social do qual o indivíduo faz parte, também é responsável pelo processo de socialização primária das crianças e dos adolescentes.

Macedo (1994) e Pratta e Santos (2007) explicam que o grupo familiar tem também um papel fundamental na organização da personalidade, além de influenciar significativamente o comportamento individual por meio das ações e medidas educativas tomadas no seu âmbito. A instituição familiar é vista como a célula inicial e principal da sociedade na maior parte do Mundo Ocidental (BIASOLI-ALVES apud PRATTA; SANTOS, 2007).

Identificamos ainda que os autores reconhecem as transformações que a família tem sofrido como um processo histórico e social. Nas últimas décadas, a estrutura familiar e o desempenho dos papéis parentais sofreram modificações consideráveis (SINGLY apud PRATTA; SANTOS, 2007). O aumento do número de uniões consensuais, de famílias chefiadas por mulheres (ou monoparentais) e de famílias reconstituídas pode ser observado, sobretudo, a partir da década de 1990 (PRATTA; SANTOS, 2007).

Apesar das transformações observadas na instituição familiar e dos mitos e tabus em relação aos arranjos familiares que fogem ao modelo tradicional (PALUDO; KOLLER, 2008), a família continua a ser uma instituição altamente valorizada, uma vez que prossegue exercendo funções essenciais durante todo o processo de desenvolvimento de seus membros (PRATTA; SANTOS, 2007). 
Qualquer composição diferente do modelo de família nuclear acaba sendo considerada por alguns como família "desestruturada", adjetivo que aparece, geralmente, para justificar a falta de condições financeiras para manter as necessidades básicas e criticar a estrutura e a configuração da família, principalmente se esta é monoparental (PALUDO; KOLLER, 2008).

Paludo e Koller (2008) alertam que o significado atribuído à família vai além destes preceitos e preconceitos. Com o objetivo de considerar as diversas formas de relações existentes, a família passa a ser definida enquanto uma instituição complexa.

A família das camadas populares

Segundo Amazonas et al. (2003), as famílias da classe trabalhadora desenvolveram uma estrutura familiar sob condições de angústia social e econômica. Embora as famílias das camadas populares busquem se aproximar do modelo familiar burguês e sofram "a influência dos valores transmitidos pelas demais camadas da população, diferem significativamente delas, pois necessitam desenvolver estratégias de sobrevivência compatíveis com suas condições de existência" (AMAZONAS et al., 2003, p. 13). Todos os membros familiares para garantir o sustento como também o cuidado de seus integrantes. Não raro, nessas famílias, os filhos são considerados por seu potencial de trabalho e renda (PÔSTER apud AMAZONAS et al., 2003).

Amazonas et al. (2003), assim como Paludo e Koller (2008), apontam que a classe trabalhadora encontra na solidariedade uma maneira de continuar existindo num contexto, geralmente, bastante opressor. Essa solidariedade não se limita ao grupo parental, pois, muitas vezes, os vizinhos se auxiliam nos cuidados das crianças para que os pais possam sair para trabalhar e sustentar o lar.

Uma característica bastante marcante nas famílias das camadas populares apontada por Macedo (1994), Amazonas et al. (2003) e Arpini e Quintana (2003) é que a maioria delas é chefiada apenas por mulheres, que, além de serem responsáveis pelos cuidados e pelo afeto, também têm a tarefa de garantir o sustento do lar. As taxas de famílias chefiadas por mulheres nas áreas urbanas têm aumentado significativamente (GOLDANI apud ARPINI; QUINTANA, 
2003). A mulher, nessas famílias, acaba tendo uma sobrecarga muito grande, seja pela obrigatoriedade de prover uma prole numerosa, seja pela necessidade de abrigar sob seus cuidados um maior número de pessoas mais velhas ou filhos jovens sem trabalho (MACEDO, 1994).

Outro aspecto que chama a atenção nessas famílias é a falta de diferenciação entre o público e o privado. A rua torna-se um prolongamento da casa e

As condições físicas da casa influenciam o prolongamento do lar para a rua. Habitações quentes, precárias, pequenas e desconfortáveis fazem com que estas famílias passem parte do seu tempo na rua e vivam muitas de suas experiências ali, junto com a comunidade (AMAZONAS et al., 2003, p. 14).

Além de oferecer proteção ao desenvolvimento de seus membros, a família também pode ser caracterizada como um fator de risco, pois os eventos de risco podem produzir maior vulnerabilidade social das famílias (SILVA apud PALUDO; KOLLER, 2008). O risco ou ainda a vulnerabilidade familiar pode acontecer em situações socioeconômicas precárias que resultam em abandono, violência, dentre outras (GOMES; PEREIRA apud PALUDO; KOLLER, 2008).

Desemprego, má nutrição, maior número de filhos na adolescência, instabilidade nas relações, abuso de drogas, violência, estresse devido à moradia inadequada e a dívidas constantes, baixo poder aquisitivo, falta de dinheiro e pouquíssimas opções de lazer fazem com que o ciclo vital dessas famílias seja uma sequência de crises que, não raro, ultrapassam os limites da capacidade adaptativa do sistema familiar (MACEDO, 1994).

Devido à necessidade da família em se manter tanto econômica quanto emocionalmente, algumas estratégias são desenvolvidas como, por exemplo, a saída de crianças e adolescestes à procura de trabalho no espaço da rua (PALUDO; KOLLER, 2008).

A criança abandonada como contrapartida da família abandonada

Corroborando as discussões levantadas por Kaloustian e Ferrari (1994) e por Gomes e Pereira (2005) de que a criança abandonada ou em situação de rua é apenas reflexo da família abandonada ou não atingida pela política social, Barros et al. (2009) consideram importante 
destacar que a problemática das crianças e dos adolescentes em situação de rua é uma questão que transcende o núcleo familiar, tornando-se um problema macrossocial provocado por questões sociais, políticas, culturais, históricas e econômicas.

O processo de saída das crianças e adolescentes do contexto familiar para as ruas, por exemplo, está relacionado, na maior parte dos casos, com a miséria quase absoluta dominante nos bolsões de pobreza periféricos ou intraurbanos (CAMARGO, 1996; ALVES-MAZZOTTI apud ARPINI; QUINTANA, 2003).

Para Camargo (1996), as condições de vida e de moradia extremamente precárias, especialmente em alguns espaços limítrofes, nos quais praticamente não existe a presença do poder público, fazem com que as crianças pobres, moradoras desses bairros de periferia, procurem a rua e os atrativos do centro da cidade. Muitas vezes, elas começam a frequentar a rua incentivadas pela própria família, com o objetivo de complementar o orçamento doméstico.

Outro fator que propicia a aproximação gradativa dessas crianças com o mundo da rua é que os pais, comumente, ficam fora de casa durante o dia todo, pela necessidade de trabalhar para garantir a manutenção e a sobrevivência familiar. As crianças ficam cerceadas de uma figura de referência na organização de seu dia a dia, provocando o que se chama de "síndrome da casa vazia" e, consequente a isso, podem, gradativamente, aproximar-se dos atrativos e da convivência encontrados na rua (MOURA apud ARPINI; QUINTANA, 2003; BARROS et al., 2009).

As crianças vão para as ruas fugindo da miséria e da violência, por falta de perspectivas ou como um gesto de superação, em resposta à situação de pobreza e ao desamparo afetivo. Assim, aos poucos, elas se desgarram não só de sua família, mas das redes de relações mais familiares que as faziam reconhecerem-se e serem reconhecidas como pertencentes a um determinado lugar (CAMARGO, 1996).

Culpabilização da família 
Guerra (apud ARPINI; QUINTANA, 2003) aponta que os pais de adolescentes das camadas populares têm vivido uma crise de identidade, sentindo-se enfraquecidos em sua função de indivíduos que servem de referência para seus filhos. Os adolescentes que integram as camadas populares, ao olharem para a vida de seus pais, acabam se deparando com uma perspectiva empobrecida, marcada pela realização de trabalhos desvalorizados e mal remunerados, que lhes impõem uma vida sem conforto. A constatação dessa situação resulta na ausência de expectativa de mudança.

O conceito de desqualificação social auxilia no entendimento desse processo de enfraquecimento da identidade paterna (PAUGAM apud ARPINI; QUINTANA, 2003). A experiência de desqualificação social é humilhante e desestabiliza as relações com o outro, afetando as interações familiares. Alguns pais, ao perceberem que não correspondem socialmente ao que se espera deles, podem experimentar um sentimento de incompetência social e de fracasso pessoal, pelo qual se acusam e são acusados.

Outra questão é que, em muitos casos, os pais trabalham fora durante o dia todo, de modo que seus filhos ficam em casa sozinhos, sem uma figura familiar de referência. Apesar de existirem alguns espaços sociais para atenderem a estas crianças, elas são consideradas como pessoas de segunda categoria, que devem ser assistidas, embora não se espere delas um futuro promissor (ARPINI; QUINTADA, 2003). Esse fenômeno revela a existência de um grande preconceito em relação às famílias pobres e, consequentemente, ao modo como elas vivem.

Esse mesmo preconceito também é apontado nas políticas públicas, pois elas ainda são consideradas bestiais/bestializadas (NEDER apud ARPINI; QUINTANA, 2003). Tais autores acrescentam que a própria sociedade, insistentemente, culpa as famílias populares por sua situação de desamparo, fracasso e passividade, porém não propicia condições fundamentais para que possam enfrentar os desafios sociais impostos. Socialmente, a história de desamparo, falta de assistência e violações, comum a todos eles, acaba sendo desconhecida/desconsiderada. Essa mesma história que os une também os inflige uma situação de exclusão e risco. 
É preciso, sem dúvida, adotar um novo modo de conceber a relação. É preciso, sem dúvida, adotar uma nova maneira de considerar a família e a pobreza, pois a situação de pobreza não faz desses pais pessoas desqualificadas e incapazes. Eles podem sim oferecer afeto, proteção e amor para seus filhos. É preciso repensar essa institucionalização da concepção de família, evitando-se a repetição da relação que a sociedade mantém com essa população e com as instituições que a atendem (ARPINI; QUINTANA, 2003).

Como a família é referenciada no contexto das políticas públicas para crianças e adolescentes

O Estado, por meio da Constituição Federal (BRASIL, 1988), reconhece a importância da família na proteção e na vida da criança e do adolescente ao afirmar que essa é a base da sociedade, e ao defender que a criança e o adolescente têm direito à convivência familiar e comunitária (COSTA; ROSSETTI-FERREIRA, 2009). Contudo, ante a falta de políticas públicas adequadas para as famílias das camadas populares atenderem às necessidades de suas crianças (FONSECA apud COSTA; ROSSETTI-FERREIRA, 2009), a rua aparece como uma alternativa ou o abrigo acaba funcionando como um "colégio interno" para as crianças pobres. ${ }^{1}$

De acordo com Paludo e Koller (2008), a situação econômica do país é fator que contribui significativamente para a saída de crianças e adolescentes para a rua. Muitas famílias sobrevivem abaixo da linha da miséria. O desemprego dos pais, o grande número de membros na família, as condições econômicas desfavoráveis, as residências, em geral, distantes dos centros comerciais entre outros, contribuem para essa migração e fazem com que essas pessoas fiquem ainda mais vulneráveis. Tais fatores contribuem, significativamente, com a saída das crianças e adolescentes para a rua em busca de dinheiro e assim ajudarem com o sustento da família.

Os pais, sem condições de manterem suas crianças, estimulam suas tentativas pela busca da sobrevivência na rua, local onde esses meninos têm a possibilidade de aprenderem a furtar, roubar e cometerem assaltos. Alguns se envolvem até mesmo com drogas e traficantes adultos (SIQUEIRA, 1996).

${ }^{1}$ Ibid. 
Santana et al. (2005), bem como Paludo e Koller (2008), destacam a importância de prevenir a ida das crianças para as ruas. Acreditam que uma intervenção direcionada a essa finalidade poderia impedir que outras crianças saíssem de suas casas e comunidades e repetissem o processo de saída para as ruas.

Além da dificuldade manifesta em prevenir os motivos pelos quais as crianças e adolescentes buscam a vivência nas ruas, Santana et al. (2005) acrescentam a dificuldade de as instituições de atendimento a esse público encontrarem serviços na própria comunidade que auxiliem na reinserção dessas crianças e adolescentes nos seus grupos familiares.

Além das crianças em situação de rua, identificamos considerações que dizem respeito à questão do abrigamento. Costa e Rossetti-Ferreira (2009) apresentam um dado bastante significativo: o Levantamento Nacional de Abrigos para Crianças e Adolescentes de 2003 estimou que em torno de 80.000 crianças e adolescentes estavam vivendo em instituições de abrigo no Brasil. Entretanto, a maioria das crianças e adolescentes dos abrigos investigados possui família $(86,7 \%)$, da qual foram afastados por situações de abandono, negligência ou violência. Tais famílias enfrentam inúmeras dificuldades quanto à sua manutenção e subsistência.

Com base no ECA, foram criados mecanismos sociais de proteção para aqueles que sofrem violência em seu ambiente doméstico que, em geral, levam ao afastamento da criança ou adolescente do ambiente familiar. A institucionalização da vítima, nos casos de violência doméstica, pode ser interpretada como mais uma violência ao seu desenvolvimento emocional e psicológico, pois, de modo geral, não são tomadas medidas de acompanhamento, orientação e apoio sociofamiliar (ANTONI; KOLLER, 2000).

Com o intuito de enfrentar e transformar essa realidade, o Ministério do Desenvolvimento Social (MDS), a Secretaria Especial de Direitos Humanos (SEDH), o Conselho Nacional dos Direitos da Criança e do Adolescente (CONANDA), o Conselho Nacional de Assistência Social (CNAS), entre outros, vêm priorizando discussões para implantar ações de fortalecimento do modelo de proteção integral à criança e ao adolescente, com vista a garantir a sua condição de pessoa em desenvolvimento bem como seus direitos. Ações assim têm como objetivo promover e manter seus vínculos comunitários e familiares, adequando-se ao que é 
estabelecido pelo Estatuto da Criança e do Adolescente (ECA) e pela Convenção sobre os Direitos da Criança, realizada em 1989, pela Organização das Nações Unidas (ONU) (COSTA; ROSSETTI-FERREIRA, 2009).

Em consonância com a reorganização da política nacional de assistência, cujo foco está voltado para a família, o governo brasileiro aprovou, em 2006, um plano com diretrizes nacionais de apoio sociofamiliar, de acolhimento familiar e institucional e de adoção, conhecido como Plano Nacional de Promoção, Proteção e Defesa do Direito de Crianças e Adolescentes à Convivência Familiar e Comunitária (COSTA; ROSSETTI-FERREIRA, 2009).

Este plano constitui um marco nas políticas públicas no Brasil, ao romper com a cultura da institucionalização de crianças e adolescentes e ao fortalecer o paradigma da proteção integral e da preservação dos vínculos familiares e comunitários preconizados pelo ECA (BRASIL, 2006, p. 14).

Assim, o acolhimento familiar, presente na Política Nacional de Assistência Social passa a ser reconhecido como parte integrante das políticas sociais do país. Para evitar a institucionalização, a criança e/ou adolescente em situação de vulnerabilidade é acolhido por um determinado período em outra família, previamente selecionada, cadastrada e vinculada a um programa. Com o objetivo da reintegração familiar, paralelamente ao acolhimento, torna-se fundamental repensar, juntamente com a família de origem, os motivos que levaram ao acolhimento e que precisam ser modificados.

Diferentemente do que discutem outros autores, que defendem a inclusão das famílias na elaboração das políticas públicas para crianças e adolescentes, Andrade (1998) defende que a infância, enquanto política de ação social, não deve estar agrupada em família, educação ou saúde. Para a autora, a criança passa a ser vista nas políticas públicas do Estado a partir do século XVIII, como extensão de seus pais e não como sujeito que tem direitos próprios. Tal concepção, para ela, permanece viva na atualidade.

A autora acrescenta ainda que a psicologia funcionou como parte aliada do Estado moderno quando esse, em função da industrialização, retira a criança do mercado de trabalho. Para Andrade, o Estado, ao retirar da criança seu poder de trabalho, reforça a ideia de proteção 
e controle da infância, assim como a ideologia de que a criança pertence aos pais, cabendo a esses a principal responsabilidade sobre aquele futuro adulto.

\section{Discussão}

Considerando o objetivo que nos propomos, identificamos, primeiramente, que a família, independentemente de sua configuração, mantém um papel específico no contexto social: continua a ser uma instituição reconhecida e altamente valorizada, uma vez que prossegue exercendo funções essenciais durante todo o processo de desenvolvimento de seus membros. Nesse sentido, consideramos oportuno o título dado ao primeiro núcleo temático analisado, "A família de todos e a de cada um".

Identificamos, mediante análises realizadas, que a família tem importância fundamental na vida de todos os indivíduos e que, apesar de essa importância ser universal, cada pessoa faz parte de uma instituição familiar com características que lhe são próprias e específicas. A família, embora importante para todos, pode ter uma configuração bastante diferente daquilo que é considerado como tradicional, e nem por isso merece ser considerada como "desestruturada", adjetivo preconceituoso muitas vezes direcionado para famílias de baixo poder aquisitivo e com configurações familiares distintas do modelo tradicional nuclear.

O segundo eixo temático, "A família das camadas populares", evidencia as necessidades de adaptação que são encontradas nessas famílias. Embora elas busquem a semelhança com o modelo de família burguesa, acabam por encontrar alternativas para sua sobrevivência como, por exemplo, o trabalho infantil para ajudar na manutenção e sustento da família. Essa, geralmente numerosa, na maioria das vezes, chefiada por mulheres, e contando com a solidariedade comunitária, devido à grande dificuldade de acesso a bens e serviços.

Outra característica marcante identificada refere-se a não diferenciação entre o público e o privado, resultante, principalmente, das péssimas condições de moradia e de infraestrutura. A rua torna-se o ponto de encontro permanente e das grandes vivências diárias dessa população. Identificamos, no segundo eixo apresentado, que, apesar da importância atribuída à família, as precárias condições socioeconômicas das famílias das camadas 
populares impõem maiores dificuldades para sua sobrevivência, o que pode agravar ou desencadear episódios de risco, como abandono, negligência e violência. Os eventos de risco podem produzir maior vulnerabilidade social nessas famílias.

Nesse sentido, consideramos oportuno apresentar os dados do terceiro eixo temático, uma vez que compreendemos, assim como os autores pesquisados, que "A criança abandonada é apenas contrapartida da família abandonada" ou não atingida pelas políticas sociais que a elas deveriam estar direcionadas. A escassez de recursos materiais e afetivos faz com que as famílias das camadas populares desenvolvam estratégias de sobrevivência, o que pode ocasionar a saída das crianças ou adolescentes para o contexto da rua na tentativa de colaborar com o sustento familiar. Assim, aos poucos, eles se distanciam não apenas de sua família, mas também das redes de relações que os faziam se reconhecer e serem reconhecidos como pertencentes a um lugar determinado. Diante de tal situação, retomamos o argumento de Barros et al. (2009), segundo os quais a problemática das crianças e dos adolescentes em situação de rua é uma questão que transcende o núcleo familiar, na medida em que se trata de um problema macrossocial, provocado por questões sociais, políticas, culturais, históricas e econômicas.

Infelizmente, embora todas estas questões sejam decorrentes de outras que, em sua maioria, independem do desejo e dos esforços das famílias das camadas populares para evitálas, é muito comum acontecer o que apresentamos no quarto eixo temático: "Culpabilização da família". Toda a privação de recursos materiais e de acesso a estruturas públicas, atrelada à realização de trabalhos mal remunerados e considerados insignificantes, muitas vezes insuficientes para o sustento familiar, faz com que esses pais sintam-se enfraquecidos em seu papel de sujeitos sociais, tornando-os fragilizados enquanto modelos de identificação. A constatação dessa situação resulta na ausência de expectativa de mudança. Assim, ao não conseguirem dar conta daquilo que se espera deles como sujeitos, esses pais vivenciam um sentimento de inferioridade social e uma sensação de não realização pessoal.

Independentemente dessa constatação, muitos pais continuam trabalhando fora durante todo o dia, e embora sejam criados alguns espaços sociais para o atendimento das crianças que não podem conviver integralmente em família, em geral, isto é feito a partir de 
uma postura de descrença em relação a essa população. Tais considerações dos autores citados nos remetem, sobretudo, às ações dos gestores das políticas públicas e dos profissionais que trabalham com a população aqui estudada. Esse fenômeno evidencia a presença de um acentuado preconceito, não apenas por parte da sociedade, mas também por parte de gestores e profissionais das políticas públicas sociais, em relação às famílias das classes populares. Infelizmente, identificamos que a família pobre continua sendo concebida como desqualificada e que os pais que integram esse grupo são vistos como incapazes de oferecer amor, proteção e afeto a seus filhos.

Por fim, no quinto eixo temático, procuramos resgatar, nos artigos pesquisados, "Como a família é referenciada no contexto das políticas públicas para crianças e adolescentes". Embora a Constituição Federal de 1988 reforce o papel da família como elemento fundamental no processo de proteção integral da criança e do adolescente, observamos a falta de políticas públicas adequadas às famílias das camadas populares. Como consequência dessas dificuldades, observamos também as crianças e adolescentes em situação de rua e ainda aquelas em situação de abrigamento. Dessas, segundo pesquisa realizada em $2003,86,7 \%$ são provenientes de famílias pauperizadas, que enfrentam inúmeras dificuldades para sua manutenção e subsistência e que, infelizmente, não foram contempladas por políticas públicas capazes de evitar a instalação da referida situação.

Também identificamos iniciativas para o enfrentamento e transformação dessa realidade com a aprovação, em 2006, do Plano Nacional de Promoção, Proteção e Defesa do Direito de Crianças e Adolescentes à Convivência Familiar e Comunitária, com o objetivo de promover e garantir os vínculos familiares e comunitários, adequando-se ao que é preconizado pelo Estatuto da Criança e do Adolescente (ECA) e pela Convenção sobre os Direitos da Criança, no ano de 2006.

Constatamos ainda que, dentre todos os autores pesquisados, somente uma autora se posiciona contrariamente a que a família esteja na centralidade das políticas públicas para crianças e adolescentes. Andrade (1998) defende que a política para infância, enquanto política de ação social, não deve estar agrupada em família, educação ou saúde. Ela argumenta que a infância, como realidade social, frequentemente tem permanecido afastada e excluída 
das reflexões sobre os problemas sociais e a qualidade de vida e das aspirações sociais coletivas. Para a autora, a criança passa a ser vista nas políticas públicas do Estado, a partir do século XVIII, como extensão de seus pais e não como sujeito que possui direitos próprios, concepção que, para ela, permanece viva na atualidade.

De modo geral, observamos que oito dos doze artigos analisados, um número bastante expressivo, fazem referência a intervenções e/ou programas voltados para crianças e adolescentes vítimas de algum tipo de violação de direitos (violência sexual, situação de rua, abrigamento, negligência e outros). Num momento em que as discussões estão na centralidade da família nas políticas públicas, na valorização do direito à convivência familiar e comunitária e no dever do Estado de assegurar políticas em que todas as famílias tenham condições mínimas de cuidar de seus dependentes, o que se lê ainda diz respeito, sobretudo, a intervenções "remediadoras", que se fazem somente após a instalação de alguma violação.

Não pretendemos aqui desmerecer ou desvalorizar a importância de ações voltadas para crianças e adolescentes, cujos direitos tenham sido violados. Tais ações precisam existir e devem ser melhoradas dia após dia. Um grande exemplo disso é a publicação do Plano Nacional de Promoção, Proteção e Defesa do Direito de Crianças e Adolescentes à Convivência Familiar e Comunitária (BRASIL, 2006), que versa sobre a centralidade da família nas políticas públicas e prioriza a responsabilidade do Estado no fomento de políticas integradas de apoio à família.

Pretendemos, sobretudo, instigar questionamentos e reflexões também muito importantes para que todas as famílias, indistintamente, tenham condições de atender a suas crianças e adolescentes com tudo o que lhes é de direito. Isso não anularia, por completo, as violações de direitos às quais crianças e adolescentes estão sujeitos, mas, certamente, reduziria as violações de direitos às quais as famílias das camadas populares estão submetidas e, consequentemente, tornaria muito melhor a convivência familiar das crianças e adolescentes inseridos nessas famílias.

A família, frequentemente considerada como aquela que fornece apoio, acolhida, proteção para seus membros, precisa dispor de alguns fatores básicos para que possa exercer com sucesso as funções a ela atribuídas. Boas condições de moradia, trabalho, renda, 
alimentação, acesso à rede de serviços públicos (habitação, escola, saúde, lazer) são apenas alguns exemplos disso.

Não obstante, o resultado da análise dos artigos revela ser muito comum as famílias, sobretudo as das camadas mais pobres, não contarem com condições mínimas para sua existência, o que resulta, muitas vezes, em dificuldades para atender às necessidades básicas de seus filhos. Desse modo, a família em situação de vulnerabilidade coloca também seus filhos e dependentes nessa mesma situação. A situação da família se reflete diretamente nas dificuldades vivenciadas pelas crianças e adolescentes, mas o que antecede e provoca tais consequências é a ausência ou a insuficiência de políticas públicas que atendam a essas famílias para que elas possam assegurar melhores condições de vida para seus dependentes.

Por fim, destacamos que, embora a Constituição Federal de 1988 e o Estatuto da Criança e do Adolescente (1990) constituam-se em marcos fundamentais para a valorização da família enquanto espaço de defesa dos direitos das crianças e adolescentes, e a formulação do Plano Nacional de Promoção, Proteção e Defesa do Direito de Crianças e Adolescentes à Convivência Familiar e Comunitária (BRASIL, 2006) seja uma conquista imprescindível e fundamental, certamente isso não representa o fim, mas apenas os passos iniciais, embora decisivos, para que a criança e o adolescente sejam considerados pertencentes a uma família que também precisa ser pensada em suas potencialidades e necessidades.

\section{Considerações finais}

Ao considerarmos o objetivo proposto para a realização deste estudo - como as famílias foram consideradas na elaboração e implementação de políticas públicas de proteção à criança e ao adolescente no período de 1990 a julho de 2010 -, verificamos certo distanciamento entre as discussões e teorias que deveriam nortear as políticas públicas, cuja centralidade deveria estar na família, e as ações de tais políticas no contexto das famílias, sobretudo daquelas famílias pertencentes às camadas populares.

A família, que deveria ocupar a centralidade em tais políticas, aparece como mera coadjuvante - para não dizer culpada - principalmente no cenário das violações de direitos 
sofridos por crianças e adolescentes. Na maioria das vezes, é considerada culpada por seu fracasso, ao passo que, em sua história de privações e inacessibilidade aos direitos, ela permanece mascarada como "família incapaz e desestruturada".

Conquanto seja fato que, desde a década de 1990, as discussões, em âmbito nacional e internacional, estejam voltadas para a importância da centralidade da família nas políticas sociais, constatamos que até o presente momento as políticas e programas sociais no Brasil têm se revelado insuficientes para atender efetivamente a esta demanda.

Por outro lado, embora tenhamos identificado esforços como o Plano Nacional de Promoção, Proteção e Defesa do Direito de Crianças e Adolescentes à Convivência Familiar e Comunitária (BRASIL, 2006), ainda temos muito que avançar para atingirmos o mínimo esperado. Precisamos, por exemplo, superar preconceitos de que a família pobre é incapaz e incompetente para cuidar e educar seus filhos, ou de que a infância pobre é sinônimo de infância perigosa, ideais que foram disseminados pelos especialistas higienistas no final do século XIX e início do século $X X$, mas que atualmente podem ser observados em algumas situações.

Compreendemos que as construções histórico-sociais, quando solidificadas, exigem um longo processo para sua desconstrução, para somente então assumir uma nova configuração. Todos os discursos e ideais que marginalizavam a família pobre e colocavam o Estado como o grande protetor dos direitos dos cidadãos acompanharam nossa sociedade desde o final do século XIX, até a constatação de que o Estado não tinha condições para assumir funções que dependiam exclusivamente da família, dentro de suas potencialidades e fragilidades. Esse fato faz com que o Estado redescobrisse a importância da família, das redes primárias e da comunidade como atores fundamentais na efetivação das políticas sociais.

A família, antes descartada, volta, principalmente a partir da década de 1990, a ser considerada como corresponsável pelo desenvolvimento dos cidadãos, não mais olhados isoladamente. As políticas públicas são direcionadas para as crianças na família, mudança de foco que foi permitida pela consolidação da Constituição Brasileira de 1988 e pelo Estatuto da Criança e do Adolescente (ECA), em 1990. Embora nobre, tal objetivo mostra-se relativamente novo quando comparado a todo o discurso disseminado anteriormente. Logo, essa mudança 
de paradigma não acontecerá de uma hora para outra. As ações e medidas dos gestores das políticas públicas, cuja centralidade esteja, de fato, na família, deverão se tornar cada vez mais claras, evidentes e eficazes, porém os gestores e executores das políticas públicas precisam levantar e defender esta bandeira.

Além disso, a academia pode desempenhar um papel importante na produção de estudos científicos que evidenciem e/ou avaliem a centralidade da família nas políticas públicas no Brasil, possibilitando, assim, que discussões e práticas histórias sejam questionadas e modificadas quando isso se fizer necessário.

Embora acreditemos na necessidade de a família ocupar a centralidade na elaboração e implementação das políticas públicas para crianças e adolescentes e que ainda é preciso trilhar um longo caminho para alcançarmos esse objetivo, não desconsideramos que o Estado tenha papel fundamental na efetivação de políticas públicas, cuja centralidade esteja, de fato, na família. Sem isso, podemos recair no erro de devolver toda a responsabilidade à família, inocentando o Estado de seus deveres para com a referida população.

Por fim, reafirmamos a importância deste estudo, por contribuir para uma compreensão da construção sócio-histórica que sempre esteve imbricada na elaboração e implementação das políticas sociais no Brasil, e por evidenciar o lugar ocupado pela família ou a ela destinado em diferentes contextos. Acreditamos ter alcançado os objetivos que nos propusemos; e se, além desses, a pesquisa nos forneceu subsídios para visualizarmos novas possibilidades de atendimento às famílias das camadas populares e a necessidade de comprometimento de todos os profissionais que trabalham com o referido público, certamente teremos atingido um grande objetivo, embora, inicialmente, não tenhamos tido essa pretensão.

\section{Referências}

AMAZONAS, M. C. L. A.; et al. Arranjos familiares de crianças das camadas populares. Psicologia em Estudo, Maringá, v. 8, n. especial, p. 11-20, 2003.

ANDRADE, Â. N. A criança na sociedade contemporânea: do 'ainda não' ao cidadão em exercício. Psicologia, Reflexão e Crítica. Porto Alegre, v. 11, n. 1, 1998. 
ANTONI, C.; KOLLER, S. H. A visão de família entre as adolescentes que sofreram violência intrafamiliar. Estudos de Psicologia, v. 5, n.2, 347-381, 2000.

ARPINI, D. M.; QUINTANA, A. M. Identidade, família e relações sociais em adolescentes de grupos populares. Revista Estudos de Psicologia, PUC-Campinas, jan/abr, v. 20, n. 1, p. 27-36, 2003.

BARDIN, L. Análise de Conteúdo. Lisboa: Edições 70. 1979.

BARROS, P. C. M. et al. Era uma casa...!? Discurso, dinâmica familiar e contingências da rua. Psicologia em Estudo, Maringá, jul/set., v.14, n. 3, p. 447-453, 2009.

BRASIL. Constituição. Constituição da República Federativa do Brasil. Brasília, DF: Senado Federal, 1988.

. Estatuto da Criança e do Adolescente. Lei Federal n. ${ }^{\circ}$ 8.069, de 13 de julho de 1990. Ministério da Justiça, Brasília, DF. 1990. . Ministério do Desenvolvimento Social \& Secretaria Especial de Direitos Humanos. Plano Nacional de Promoção, Proteção e Defesa do Direito de Crianças e Adolescentes à Convivência Familiar e Comunitária. Brasília, Distrito Federal: nov./2006.

BOCK, A. M. B. A Psicologia a caminho do novo século: identidade profissional e compromisso social. Estudos de Psicologia, v. 4, n. 2, p. 315-329,1999.

CALDERÓN, A. I.; GUARÁ, I. M. F. R.; CARVALHO, M. C. B. Guarda familiar: desafios e propostas. São Paulo: IEE PUC/SP/CBIA, 1994.

CAMARGO, J. Crianças na cidade: políticas públicas e universo cultural. Cadernos de Pesquisa, n. 96, p. 50-57, São Paulo, fev. 1996.

CARVALHO, M.C.B. Família e políticas públicas. In.: ACOSTA, A.R.; VITALE, M.A.F. (Org.). Família: redes, laços e políticas públicas. São Paulo, IEE/PUC-SP, p. 267-274. 2003.

CARVALHO, I. M. M. de; ALMEIDA, P. H. de. Família e proteção social. Perspectiva. São Paulo, v.17, n.2, p. 109-122, 2003.

COSTA, N. R. A.; ROSSETTI-FERREIRA, M. C. Acolhimento familiar: uma alternativa de proteção para crianças e adolescentes. Psicologia: reflexão e crítica, v. 22, n. 1, 111-118, 2009.

CUNHA, M. C. P. O espelho do mundo: Juqueri, a história de um asilo. Rio de Janeiro: Paz e Terra, 1986. 
FACHINETTO, N. J. O direito à convivência familiar e comunitária: contextualizando com as políticas públicas (in)existentes. Porto Alegre: Livraria do Advogado, 2009.

GOMES, M. A.; PEREIRA, M. L. D. Família em situação de vulnerabilidade social: uma questão de políticas públicas. Ciência \& Saúde Coletiva. v. 10, n. 2, p. 357-363, 2005.

GUEIROS, D. A. Família e proteção social: questões atuais e limites da solidariedade familiar. Serviço Social e Sociedade, 71. São Paulo: Cortez, Ano XXI. Especial. p.102-121. 2002.

HILLESHEIM, B.; CRUZ, L. R. Risco, vulnerabilidade e infância: algumas aproximações. Psicologia \& Sociedade, v. 20, n. 2, p. 192-199, 2008.

KALOUSTIAN, S. M. (Org.). Família brasileira: a base de tudo. São Paulo: Cortez; Brasília, DF: UNICEF, 1994.

KALOUSTIAN, S. M., FERRARI, M. Introdução. In.: KALOUSTIAN, S.M. (Org.). Família brasileira: a base de tudo. São Paulo: Cortez; Brasília, DF: UNICEF, p. 11-15, 1994.

MACEDO, R. M. A família do ponto de vista psicológico: lugar seguro para crescer?. Cadernos de Pesquisa, São Paulo, n. 91, p. 62-68, nov. 1994.

MARTINS, J. S. (Org.). O massacre dos inocentes: a criança sem infância no Brasil. 2 ed. São Paulo: Editora Hucitec, 1993.

MINAYO, M. O desafio do conhecimento: pesquisa qualitativa em saúde. Rio de Janeiro: Hucitec-Abrasco, 1993.

MIOTO, R. C. T. Família e serviço social: contribuições para o debate. Serviço Social e Sociedade, São Paulo: Cortez, v. 55, Ano XVIII, p. 114-129. nov./1997.

OLIVEIRA, M. L. M. Família: concepções e contextos de violência - parâmetros de atuação. In: Capacitação dos Assessores Locais do PAIR - 28 a 30 de setembro de 2009, Brasília - DF, p. 113-122. 2009.

PALUDO, S. S.; KOLLER, S.H. Toda criança tem família: criança em situação de rua também. Psicologia e Sociedade, v. 20, n. 1, 42-52, 2008.

PETRINI, J. C. Pós-modernidade e família. Bauru: Ed. Edusc, 2003.

PRATTA, E. M. M.; SANTOS, M. A. Família e adolescência: a influência do contexto familiar no desenvolvimento psicológico de seus membros. Psicologia em Estudo, Maringá, v. 12, n. 2, p. 247-256, maio/ago, 2007.

SANTANA, J. P. et al. . É fácil tirar a criança da rua, o difícil é tirar a rua da criança... Psicologia em Estudo, Maringá, v. 10, n. 2, p. 165-174, mai/ago, 2005. 
SERAPIONI, M. O papel da família e das redes primárias na reestruturação das políticas sociais. Ciência \& Saúde Coletiva, v. 10, p. 243-253, 2005.

SILVA JUNIOR, N. G. S.; ANDRADE, A. N. É melhor pra você! Normatização social da infância e da família no Brasil. Revista do Departamento de Psicologia - UFF. v.19, n. 2, p. 423-438, jul/dez. 2007.

SIQUEIRA, M. D. A vida escorrendo pelo ralo: as alternativas de existência dos meninos de rua. Estudos de Psicologia, Natal, v. 2, n. 1, 161-174. 1996.

Recebido em: 23/10/2012

Aprovado em: 30/11/2012 